\title{
Review on Fiber Digestion in Non Ruminant Animals and Effect of Dietary Fiber
}

\section{Negasu Gamachu Dinsa}

Jimma University, Department of Animal Science, Post graduate student, Jimma University, Ethiopia .

*Corresponding Author: Negasu Gamachu Dinsa, Jimma University, Department of Animal Science, Post graduate student, JimmaUniversity, Ethiopia.

\begin{abstract}
Dietary fiber is a significant in different feeds and feed ingredients of animal feedstuffs, which has a major impact on their physico-chemical properties and digestion and fermentation characteristics in the gastro intestinal tract. Dietary fiber has an important role in pig and poultry diets and a minimum level of dietary fiber has to be included to maintain normal physiological function in the digestive tract. The presence of soluble dietary fiber in the diet increases digesta viscosity and increased viscosity in the digesta can limit the interaction between nutrients and enzymes facilitating the formation of an unstirred water layer in the intestinal surface, thereby creating a physical barrier and consequently, reducing nutrient digestion and absorption. Dietary fiber affects nutrients and energy digestibility in pigs with different types.therefore Considerable additional research is still needed in order to use dietery fiber feed resources with their potential to efects in the gastro intestinal tract non ruminant animals.
\end{abstract}

Keywords: Dietary fiber;non ruminant; digestion

Abbreviations:

$\begin{array}{ll}\text { AACC } & \text { American Association of Cereal Chemists } \\ \text { ADF } & \text { Acid Detergent Fiber } \\ \text { ATP } & \text { Adenine Tri Phosphate } \\ \text { AX } & \text { Arabinoxylan } \\ C H 4 & \text { Methane } \\ \text { CHO } & \text { Carbohydrate } \\ \text { CO2 } & \text { Curbon dioxide } \\ C P & \text { Crude Protein } \\ \text { DE } & \text { Digestible Energy } \\ \text { DF } & \text { Dietary Fiber } \\ D M & \text { Dry Matter } \\ \text { GIT } & \text { Gistro Intestinal Tract } \\ H 2 & \text { Hydrogen } \\ H 2 O & \text { Water } \\ N D F & \text { Neutral Detergent Fiber } \\ N S P & \text { Non-Starch Polysaccharides } \\ \text { PH } & \text { potential of Hydrogen } \\ R S & \text { Resistant Starch } \\ \text { SBP } & \text { Sugar Beet Pulp } \\ S C F A & \text { Short Chain Fatty Acids } \\ V F A & \text { Wolatile Fatty Acids } \\ \text { WHC } & \\ & \end{array}$

\section{INTRODUCTION}

The term 'dietary fiber' was first used by Hipsley in 1953 (De Vries et al., 1999) for 'the nondigestible constituents that make up the plant cell wall'. Therefore, an important aspect of the 
definition is that DF consists of $\mathrm{CHO}$ that are indigestible by endogenous animal enzymes (AACC, 2001).

In the simplest form, carbohydrates can be separated into two basic groups based upon their digestibility in the GI tract. The first group (i.e., starch, simple sugars, and fructans) is easily hydrolyzed by enzymatic reactions and absorbed in the small intestine. These compounds can be referred to as non-structural carbohydrates, non-fibrous polysaccharides (NFC) or simple carbohydrates. The second group (i.e., cellulose, hemicelluloses, lignin, pectin and beta-glucans) are resistant to digestion in the small intestine and require bacterial fermentation located in the large intestine. These compounds can be referred to as complex carbohydrates, non-starch polysaccharide (NSP) or structural carbohydrates and are reflective in Neutral Detergent Fiber (NDF) and Acid Detergent Fiber (ADF) analysis. NDF consists of cellulose, hemicelluloses and lignin while ADF consists of cellulose and lignin. However, NDF and ADF analysis are used primarily for animal nutrition and the analysis of roughages.

Therefore, an important aspect of the definition dietary fiber plant polysaccharides and lignin that are not hydrolyzed by endogenous enzymes of the mammalian digestive system (AACC, 2001; Theander et al., 1994). According to this nutritional concept, the term dietary fiber refers to those polysaccharides that escape enzymatic digestion of the host animal including resistant starch, soluble and insoluble fiber as well as lignin. Differentiation of soluble and insoluble fiber components has helped elucidate the physiological effects of crude fiber as the two sub classes have different roles in the digestive/absorptive processes within the gastrointestinal tract.

Dietary fiber has an important role in pig and poultry diets and a minimum level of dietary fiber has to be included to maintain normal physiological function in the digestive tract (Wenk C, 2001).A major concern when including fiber in diets for mono-gastric animals is that high dietary fiber content is associated with decreased nutrient utilization and low net energy values (Noblet $\mathbf{J}$ et al., 2001). However, the negative impact of dietary fiber on nutrient utilization and net energy value will be determined by the fiber properties and may differ considerably between fiber sources. Moreover, dietary fiber may have other positive effects such as to stimulate gut health, increase the satiety, affect behavior and overall improve animal well-being (Bach Knudsen KE.et al., 2012; Wenk C, 2001).

\section{Digestion OF Dietary Fiber by Non-RUMinant ANimals}

Digestibility of DF is more variable $(40.0 \%$ to $60.0 \%)$ and lower than that of other nutrients like starch, sugars, fat and CP (above $80.0 \%$ in general). It is negatively affected by the amount and source of DF content in the diet (Noblet, 2007; Jha et al., 2010). DF is lignin and polysaccharides that are not digested by endogenous secretions of the digestive tract of man including others non-ruminat animals Trowell et al. (1976). In this nutritional context, the term DF includes any polysaccharide reaching the hindgut and so includes resistant starch (RS), and non-starch polysaccharides (NSP). NSP can be further subdivided into the two general groups of soluble and insoluble. This grouping is based on chemical, physical, and functional properties.

Starch is composed of amylase and amyl pectin, which contain $\alpha-(1-4)$ and $\alpha-(1-6)$ glucosidic linkage, respectively that are susceptible to hydrolysis by the salivary and pancreatic $\alpha$-amylase in the small intestine. However, the hydrolysis is not always complete, and forms of starch, named RS, escape digestion in the small intestine, as demonstrated in humans by Englyst and Cummings (1985).

The major polysaccharides of NSP are cellulose, pectins, beta glucans, pentosans and xylans. None of these are beta-glucan, and cannot be hydrolyzed by any endogenous enzymes of non-ruminant animals.

The type and origin of dietary fiber greatly influences the site and degree to which it can be degraded mainly depending on the degree of lignifications, solubility and structure of the NSP (Bach Knudsen, 2001). In general, both soluble and insoluble dietary fiber can be degraded by intestinal bacteria, but soluble fiber is more easily, rapidly and completely fermented than insoluble (Bach Knudsen and Hansen, 1991). The higher ferment ability of soluble fiber (e.g. pectin, gums, $\beta$-glucans) can be attributed to its higher water-holding capacity allowing bacteria to easily penetrate the matrix and start degradation. Thus, with diets containing high soluble fiber levels, the microbial activity is generally increased (Bach Knudsen et al., 1991). By contrast, insoluble fiber (e.g. cellulose) cannot be 
penetrated easily by bacteria which limits its microbial breakdown in comparison to the soluble fraction (Schneeman, 1987).Hence, degradation of insoluble dietary fiber takes longer, occurring along the full length of the LI. Lignin is neither digestible for enzymes in the small intestine nor fermentable for intestinal bacteria (Graham et al., 1986), but it influences the ferment ability of other fibrous components of the diet. As cellulose and lignin are closely associated within plant cell walls, cellulose becomes less accessible for microbial attack which depresses the rate and degree of fermentation in the LI.

There is general agreement that a major proportion of dietary NSP leaves the small intestine nearly intact, and is fermented in the large intestine (cecum and colon) by the commensal micro flora.

A numerically great and diverse range of micro flora is found in the large intestine of non-ruminant animals, including members of genera such as Bacteroides, Prevotella, Eubacterium, Lactobacillus, Fusobacterium, Peptostreptococcus, Selenomonas, Megasphaera, Veillonella and Streptococcus (Jensen, 1999). DF that is the main bacterial substrate. This understanding enables a degree of control and manipulation over the processes of gut fermentation through food composition. Bacteria exist in different micro habitats including the lumen of the gastrointestinal tract, the mucus layer and mucosal surface (Salanitro et al., 1977). Differences in bacterial population's between these micro habitats have been observed (Pryde et al., 1999).

The concentration of the microbial population in the large intestine is more than $10^{10}$ viable bacteria per gram of digesta in animals and humans, and contains more than 500 different species (Jensen, 2001).

\section{Fiber Fermentation and Production of Metabolites}

Fermentation of DF is more variable than digestion of the macro-nutrients starch, fat and CP (generally above $80.0 \%$; Bach Knudsen et al., 2008).

The most important factors influencing the ferment-ability of DF include the source of DF, solubility, degree of lignifications, processing, the level of inclusion in the diet, intestinal transit time, the age and weight of the animal and the microbial. (Bach Knudsen and Hansen, 1991; Jensen, 1999, 2001; Houdijk et al., 1999; Williams et al., 2001). Also due to changes in composition physico-chemical properties of DF such as bulk, viscosity and Water holding capacity. Soluble DF has, in general, a higher WHC than insoluble DF those give raise to a larger surface area and thereby large areas for bacterial enzyme attack. Thus, these characteristics are directly dependent on the botanical origin and/or processing of the DF source (Johansen et al., 1997).

The presence of soluble DF in the diet increases digesta viscosity (Gallaher et al., 1999) and increased viscosity in the digesta can limit the interaction between nutrients and enzymes facilitating the formation of an unstirred water layer in the intestinal surface, thereby creating a physical barrier and consequently, reducing nutrient digestion and absorption.

The role of lignin is also well documented. Fermentation of NSP is much higher for cell material from non-lignified material (wheat flour, rye flour, oat bran, sugar-beet pulp) than it is from lignified materials (per carp from rye or wheat, wheat bran), as shown in the pig (Bach Knudsen and Hansen, 1991) and in man (Stephen, 1994).It can be concluded that DF content negatively affects nutrient and energy digestibility, which varies according to the amount and source of DF and their physicochemical properties. Moreover, different types of DF also exert their effect on different physiological functions in the gut.

The main products of fermentation of DF are short chain fatty acids (SCFA), predominantly acetate, propionate and butyrate, lactate and succinate, as well as $\mathrm{H}_{2} \mathrm{O}$, various gases $\left(\mathrm{CO}_{2}, \mathrm{H}_{2}, \mathrm{CH}_{4}\right.$, ) and bacterial cell biomass (Macfarlane GT and Macfarlane S, 1993; Williams et al., 2001). Acetate is the most abundant VFA, comprising about $60.0 \%$ of the total VFA produced in the hindgut, whereas propionate and butyrate are produced in smaller quantities (Lunn and Buttriss, 2007)

\section{DieTARY FibER DigesTIBILITY IN THE UPPER AND LOWER GUT}

\subsection{Fiber Digestibility in the Upper Gut}

DF escapes enzymatic digestion in the small intestine and becomes available for fermentation by bacteria in the colon. Fiber-degrading bacteria are present in the stomach and in the proximal small 
intestine. They can partially disrupt the cell wall components of fiber, which leads to partial digestion (Varel and Yen, 1997).

Gdala et al. (1997) reported lower digestibility of xylose, arabinose and uronic acids in the small intestine of piglets compared with glucose when fed diets based on cereals and soybean meal. This might be due to the high digestibility of mixed linked $\beta \mathrm{G}$, which is highly degradable in the upper gut, due to its soluble nature (Bach Knudsen and Hansen, 1991; Jha et al., 2010, 2011b).

\subsection{Fiber Digestibility in the Lower Gut}

Among the NSP components, soluble $\beta$-Glutan, Arabinoxylan (AX), and pectin are rapidly degraded in the cecum and proximal colon while insoluble components of NSP like cellulose and insoluble AX are degraded slowly and at the distal part of the colon (Bach Knudsen et al., 1993a; Glitsø et al., 1998; Canibe and Bach Knudsen, 2002).

\subsection{Effects of Dietary Fiber on Intestinal Physiology}

Effects of the presence of DF on the digestibility of amino acids, endogenous losses and digestibility of other nutrients have been well documented, especially in adult animals including the pig (Pluske et al., 2001), poultry (Choct and Annison, 1990), and man (Nordgaard and Mortensen, 1995).

The presence of soluble DF in the diet increases digesta viscosity (Gallaher et al., 1999) and increased viscosity in the digesta can limit the interaction between nutrients and enzymes facilitating the formation of an unstirred water layer in the intestinal surface, thereby creating a physical barrier and consequently, reducing nutrient digestion and absorption. Consequently, an increase in intestinal viscosity might reduce the digestion and absorption of nutrients in the diet (Molist et al., 2014). In this respect, Lizardo et al. (1997) reported decreasing apparent ileal digestibility in 25-day-old piglets fed a control diet or a same diet supplemented with $12.0 \%$ sugar beet pulp (SBP). In presence of DF, there is also an increase in the pancreatic secretions and the number of goblet cells (Schneeman et al., 1982). Moreover, there is increase in mucus secretion in the small intestine (Mariscal-Landin et al., 1995), which might be due to the mechanical effect of DF on the gut wall that affects the integrity of the mucus layer, resulting in superficial cell lesions (Schmidt-Willig et al., 1996). Insoluble DF sources such as WB are relatively resistant to microbial degradation (Jorgensen et al., 1996) and its inclusion in the diet produces an increase in fecal DM and bulkiness.

In general soluble fiber increases intestinal transit time, delays gastric emptying, delays glucose absorption, increases pancreatic secretion, and slows absorption, whereas insoluble fiber decreases transit time, enhances water holding capacity and assists faecal bulking in non-ruminant animals

\subsection{Effect of Dietary Fiber on Gut Microbiota and Microbials}

The influence of diet on microbial communities in the pig intestines has been of interest for long time. However, the interaction of diet and microbiota in the intestines of the pig are still not well understood. The GIT microbiota of pig is composed primarily of bacteria. The microbial population increases from $10^{3}$ to $10^{5} / \mathrm{g}$ of digesta in the stomach to $10^{9}$ to $10^{10}$ in the distal small intestine, and further to $10^{10}$ to $10^{11}$ in the large intestine of pigs, belonging to more than 50 genera and over 500 species of bacteria (Jensen and Jorgensen, 1994; Gaskins, 2001). The majority (about 90.0\%) of the cultivable bacteria are Gram-positive, strict anaerobes belonging to the Streptococcus, Lactobacillus, Eubacterium, Clostridium and Peptostreptococcus genus while the remaining 10.0\% of total flora belongs to Gram-negative of Bacteroides and Prevotella groups (Gaskins, 2001). Each bacterial species occupies a particular niche with numerous interrelationships between them (Flint et al., 2008). Microbial composition, population and their activities in the gut are influenced by several factors, the main one being diet (Bach Knudsen et al., 2012).

More specifically, the structure and composition (Bindelle et al., 2010), solubility (Hogberg and

Lindberg, 2004) and amount and type of substrate available (Macfarlane and Macfarlane, 1993) affects the gut microbial ecology. Among the different constituents of diets, DF is found to affect the gut environment (Jha et al., 2010). The source of DF affects the digestion site and gut environment, thereby affecting the conditions for the proliferation of microbiota in the gut (Hogberg and Lindberg, 2004). Moreover, DF serves as an energy source for microbes and supports their proliferation. 
Gidenne (2015) reported that the energy provided by the cecal VFA could reach up to $50 \%$ of the maintenance energy in growing rabbit. In pigs, Bach Knudsen et al. (1991) reported 5.5 times (as measured by ATP concentration) increased microbial activity in the GIT of pigs when fed with a high-fiber diet. In addition, there was increased (five to nine times) carbon dioxide and methane production, suggesting increased microbial fermentation that takes place in the GIT of pigs fed a highfiber diet. Similar increased microbial activity was observed in the intestines of pigs fed pea fiber and pectin, as indicated by higher bacterial counts, ATP concentration, adenylate energy charge and low pH (Jensen and Jorgensen, 1994). However, Varel et al. (1982) noted that there was initially a decrease in the bacterial population of the pig intestines when the animals were fed with high-fiber diet $(50.0 \%$ alfalfa meal) in lean genotype pigs. The microbial population, however, increased after continuous fiber-feeding for 17 weeks. It suggests that there is some kind of adaptation of the microbiota in the pig intestines when fed with high DF diets. DF affects fermentation in the GIT by stimulating the growth or metabolism of special bacterial species (Williams et al., 2001). These increased numbers of cellulolytic bacteria enhance the hindgut fermentation and production of VFA, which decreases the $\mathrm{pH}$ of the gut content. A decrease in $\mathrm{pH}$ promotes growth of beneficial bacteria (e.g. bifid bacteria spp., Lactobacilli spp.), at the expense of pathogenic ones like Clostridium or Salmonella, which contribute to enhance the health of host species (Bouhnik et al., 2004).

\subsection{Effect Dietary Fiber on Gut Health of Mono Gastric Animals}

DF plays an important role in the function of the pig GIT. It is evidenced by several studies reporting the positive role of DF in controlling bacterial infections, particularly reducing post-weaning diarrhea (Williams et al., 2001).

Thomsen et al. (2007) observed that the inclusion of DF, like fructan-rich chicory roots and sweet lupins completely protected against the development of swine dysentery. Similarly, the inclusion of DF in piglet diets enhanced intestinal populations of Lactobacilli spp. And reduced the incidence and severity of diarrhea (Edwards, 1996). These studies support the view that diets supplemented with fiber can protect pigs against swine dysentery. However, there is continuous debate on whether fiber exerts beneficial or detrimental effects on the development of post weaning nteric infection of the intestines with bacteria or protozoan's. Similar negative effect on gut health was also noticed with supplementation of isolated soluble fiber. Nursery pig diets supplemented with $0.025 \% \beta G$ increased growth performance but also increased the susceptibility to Streptococcus infection (Dritz et al., 1995). These authors suggest that a complex interaction exists between growth performance and disease susceptibility in pigs fed $\beta$ G.It can be summarized that the presence of fiber in the gut significantly affects the gut microbial environment, creates more favorable lumen conditions for gut health by stimulating the growth of 'beneficial bacteria' at the cost of 'harmful bacteria', with the possibility of some negative impact on gut health, which depends on the type of fiber substrate available for fermentation. However, there is no straightforward answer of the benefits of DF on gut health and direct evidence for enhanced resistance to unfavorable conditions is still lacking.

\subsection{Effect Dietary Fiber on Energy Loss and Metabolic Utilization of SCFA}

Increased DF level is associated with a reduced metabolisable energy content of the feed (Noblet et al., 2001). The overall energy cost in terms of heat production associated with the ingestion and excretion of indigestible fibrous ingredients is minimal and cannot be considered as significant (De Lange et al., 2006). Nevertheless, beside the unfermented DF, the main loss of energy due to DF is ascribed to the gases of fermentation $(\mathrm{CH} 4, \mathrm{H} 2$ and $\mathrm{CO} 2)$, the heat of fermentation and the heat due to metabolic utilization of SCFA. A significant part is also lost as bacterial biomass in the faeces. Even though it has not been clearly quantified yet, this loss was estimated to 0.2 of the neutral detergent fiber (NDF) energy content or 0.5of the energy content of digestible NDF (Noblet et al.,2001). Average energy loss as methane ranges from 0.001 to 0.012 of the gross energy, the highest values being obtained with diets rich in highly digestible DF sources (soybean hulls or sugar beet pulp) (Noblet, 2001). Sows loose a higher proportion of digestible energy (DE) as methane than growing pigs at the same dietary level of fiber (Jørgensen, 2007).

\subsection{Effect on Animal Voluntary Intake and Performances}

The bulking capacity of DF reduces the transit time in the entire gastrointestinal tract and the digestibility of the other nutrients of the diet. An increase in fiber content decreases the mean retention time in the small and the large intestines (Wilfart et al., 2007), reducing the time of exposure of the diet to the host's digestive enzymes (Low, 1982). 


\subsection{Effect on Total Tract and Ileal Protein Digestibility}

In the case of inclusion of rapidly fermentable NSPs such as from sugar beet pulp or pectin in the pig diet, both fecal and ileal apparent digestibility of protein and/or amino acids decreased ( Zervas and Zijlstra, 2002a). The reduction in ileal digestible protein supply due to soluble fiber might be caused by pectin and other gel-forming polysaccharides by reducing absorbed by amino acids and peptides, withholding these from absorption (Mosenthin et al., 1994).

Dietary inclusion of NDF is also believed to negatively affect both the ileal and total tract apparent digestibility of protein and amino acids (Lenis et al., 1996; Yin et al., 2000). However, comparing the effect of soluble and insoluble NSP on the digestibility of protein, Robertfroid (1993) reported that soluble NSP (like pectin) were expected to have a larger negative effect than insoluble NSP (NDF).

\subsection{Effect of Dietary Fiber on Fat Digestibility}

Soluble DF depresses the digestibility of fat by means of changing the viscosity of the digesta.

Increasing dietary fiber decreases the fat digestibility or alternatively, increasing fat content reduces fermentation in the hind gut and results in a lower fiber digestibility.

\section{CONCLUSION}

In this context, moderate levels of DF in diets for young non-ruminant animals seem to be beneficial for gut health. Such an intake may reduce the incidence and duration of infectious diarrhea, and favorer hydration.

There is wide variation found in the composition of DF in different feeds and feed ingredients, which has a major impact on their physico-chemical properties and digestion and fermentation characteristics in the GIT. In general, DF affects nutrients and energy digestibility in pigs negatively but with differences between the different types: (1) soluble DF fractions are fermented faster than insoluble fractions, produce higher amounts of VFAs and lower ammonia concentrations; (2) some DF constituents, for example RS, may stimulate butyrate production to a higher degree than others by that means contributing to an improved gut health; and (3) some DF constituents may exert 'prebiotic effects', enhancing 'beneficial bacteria' at the cost of 'harmful bacteria' in the pig gut. Therefore, strategic selection of DF in diets can be used as a nutritional strategy to modulate the intestinal health of swine.

\section{REFERENCES}

[1]. American Associate of Cereal Chemists 2001. The definition of dietary fiber. AACC report. American Association of Cereal Chemists 46, 112-126.

[2]. Bach Knudsen, K. E. 2001. The nutritional significance of "DF" analysis. Anim. Feed Sci.Technol. 90:3-20.

[3]. Bach Knudsen, K. E. and I. Hansen. 1991. Gastrointestinal implications in pigs of wheat and oat fractions. 1. Digestibility and bulking properties of polysaccharides and other major constituents. Br. J. Nutr. 70: 537-556.

[4]. Bach Knudsen, K. E., B. B. Jensen and I. Hansen. 1991. Gastrointestinal implications in pigs of wheat and oat fractions. 2. Microbial activity in the gastrointestinal tract. Br. J. Nutr. 65:233-248

[5]. Bach Knudsen K.E., Hedemann M.S., Laerke H.N., 2012. The role of carbohydrates in intestinal health of pigs. Anim. Feed Sci. Technol. 173: 41-53

[6]. Bach Knudsen KE, Laerke HN and Jorgensen H 2008. The role of fiber in nutrient utilization and animal health. In Proceedings of the 29th Western Nutrition Conference, September 23-24, Edmonton, AB, Canada, pp. 93-107.

[7]. Bindelle J, Pieper R, Leterme P, Rossnagel B and Van Kessel AG 2010. Changes in intestinal microbial ecophysiology as related to the carbohydrate composition of barleys and oats cultivars in an in vitro model of the pig gastrointestinal tract. Livestock Science 133, 151-153.

[8]. Bouhnik Y, Raskine L, Simoneau G, Vicaut E, Neut C, Flourié B, Brouns F and Bornet FR 2004. Capacity of nondigestible carbohydrates to stimulate bifidobacteria in healthy humans. American Journal of Clinical Nutrition 80, 1658-1664.

[9]. Choct, M., Annison, G., 1990. Anti-nutritive effect of wheat pentosans in broiler chickens: role of viscosity and gut microflora. Br. Poultry Sci. 33, 821-834. 
[10]. DeVries JW, Prosky L., Li B. and Cho S 1999. A historical perspective on defining dietary fiber. Cereal Foods World 44, 367-369.

[11]. Dritz SS, Shi J, Kielian TL, Goodband RD, Nelssen JL, Tokach MD, Chengappa MM, Smith JE and Blecha F 1995. Influence of dietary beta-glucan on growth performance, nonspecific immunity, and resistance to Streptococcus suis infection in weanling pigs. Journal of Animal Science 73, 3341-3350.

[12]. Englyst, H.N., Cummings, J.H., 1985. Digestion of the polysaccharides of some cereal foods in the human small intestine. Am. J. Clin. Nutr. 44, 42-50.

[13]. Flint HJ, Bayer EA, Rincon MT, Lamed R and White BA 2008. Polysaccharide utilization by gut bacteria: potential for new insights from genomic analysis. Nature Reviews Microbiology 6, 121-131.

[14]. Gallaher DD, Wood KJ, Gallaher CM, Marquart LF and Engstrom AM 1999. Intestinal contents supernatant viscosity of rats fed oat-based muffins and cereal products. Cereal Chemical 76, 21-24.

[15]. Gaskins HR 2001. Intestinal bacteria and their influence on swine growth. In Swine nutrition, 2nd edition (ed. AJ Lewis and LL Southern), pp. 585-608. CRC Press, Boca Raton, FL, USA.

[16]. Gdala J, Johansen HN, Bach Knudsen KE, Knap IH, Wagner P and Jørgensen OB 1997. The digestibility of carbohydrates, protein and fat in the small and large intestine of piglets fed non-supplemented and enzyme supplemented diets. Animal Feed Science and Technology 65, 15-33.

[17]. Gidenne T 2015. Dietary fibres in the nutrition of the growing rabbit and recommendations to preserve digestive health: a review. Animal 9, 227-242.

[18]. Graham, H., K. Hesselman and P. Åman. 1986. The influence of wheat bran and sugar-beet pulp on the digestibility of dietary components in a cereal-based pig diet. J. Nutr. 116:242-251.

[19]. Hogberg A and Lindberg JE 2004. Influence of cereal non-starch polysaccharides on digestion site and gut environment in growing pigs. Livestock Production Science 87, 121-130.

[20]. Houdijk, J.G.M., Bosch, M.W., Tamminga, S., Verstegen, M.W.A, Berenpas, E.B, Knoop, H., 1999. Apparent ileal and total-tract nutrient digestion by pigs as affected by dietary nondigestible oligosaccharides. J. Anim. Sci. 77, 148-158.

[21]. Jensen, B.B., 1999. Impact of feed composition and feed processing on the gastrointestinal ecosystem in pigs.

[22]. Jensen, B. B., 2001. Possible ways of modifying type and amount of products from microbial fermentation in the gut. In: Gut environment of pigs (Ed. A. Piva, K. E. Bach Knudsen and J. E.

[23]. Lindberg). Nottingham University Press, Nottingham, UK. pp. 181-199.

[24]. Jensen BB and Jorgensen H 1994. Effect of dietary fiber on microbial activity and microbial gas production in various regions of the gastrointestinal tract of pigs. Applied and Environmental Microbiology 60, 1897-1904.

[25]. Jha R, Rossnagel B, Pieper R, Van Kessel A and Leterme P 2010. Barley and oat cultivars with diverse carbohydrate composition alter ileal and total tract nutrient digestibility and fermentation metabolites in weaned piglets. Animal 4,724-731.

[26]. Johansen HN, Bach Knudsen KE, Wood PJ and Fulcher RG 1997. Physicochemical properties and the degradation of oat bran polysaccharides in the gut of pigs. Journal of the Science of Food and Agriculture 73, 81-92.

[27]. Jorgensen H, Zaho X and Eggum B 1996. The influence of dietary fibre and environmental temperature on the development of the gastrointestinal tract, digestibility, degree of fermentation in the hind-gut and energy metabolism in pigs. British Journal of Nutrition 75, 365-378.

[28]. Lenis, N.P., Bikker, P., van der Meulen, J., van Diepen, J.T., Bakker, J.G., Jongbloed, A.W., 1996. Effect of dietary neutral detergent fiber on ileal digestibility and portal flux of nitrogen and amino acids and on nitrogen utilization in growing pigs. J. Anim. Sci. 74, 2687-2699.

[29]. Lizardo R, Peiniau J and Aumaitre A 1997. Inclusion of sugar beet pulp and change of protein source in the diet of the weaned piglet and their effects on digestive performance and enzymatic activities. Animal Feed Science Technology 66, 1-14.

[30]. Low A.G., 1982. Digestibility and availability of aminoacids from feedstuffs for pigs: a review. Livest. Prod.Sci., 9, 511-520.

[31]. Lunn J and Buttriss JL 2007. Carbohydrates and dietary fibre. Nutrition Bulletin 32, 21-64. Louis P, Scott

[32]. Macfarlane GT and Macfarlane S 1993. Factors affecting fermentation reactions in the large bowel. Proceedings of the Nutrition Society 52, 367-373.

[33]. Mariscal-Landin G, Seve B, Colleaux Y and Lebreton Y 1995. Endogenous amino nitrogen collected from pigs with end-to-end ileorectal anastomosis is affected by the method of estimation and altered by dietary fiber. Journal of Nutrition 125, 136-146. 
[34]. Molist F, van Oostruma M, Pérez JF, Mateos GG, Nyachoti CM and van der Aar PJ 2014. Relevance of functional properties of dietary fibre in diets for weanling pigs. Animal Feed Science and Technology 189, $1-10$.

[35]. Mosenthin, R., Sauer, W.C., Ahrens, F., 1994. Dietary pectin's effect on ileal and fecal amino acid digestibility and exocrine pancreatic secretions in growing pigs. J. Nutr. 124, 1222-1229.

[36]. Noblet J, Le Goff GI 2001. Effect of dietary fibre on the energy value of feeds for pigs. Anim. Feed Sci. Technol., 90: 35-52

[37]. Noblet J 2007. Recent developments in net energy research for swine. Advances in Pork Production. In Proceedings of the 2007 Banff Pork Seminar, January 16-19, University of Alberta, Edmonton, AB, Canada, pp. 149-156.

[38]. Nordgaard,I., Mortensen, P.B., 1995. Digestive processes in the human colon. Nutrition 11, 3745.

[39]. Pluske, J.R., Kim, J.C., McDonald, D.E., Pethick, D.W., Hampson, D.J., 2001. Non-starch polysaccharides in the diets of young weaned piglets. In: Varley, M.A., Wiseman, J. (Eds.), The Weaner Pig: Nutrition and Management. CABI publishing, Wallingford, pp. 81-112.

[40]. Pryde, S. E., A. J. Richardson, C. S. Stewart and H. J. Flint. 1999. Molecular analysis of the microbial diversity present in the colonic wall, colonic lumen, and caecal lumen of a pig. Appl. Environ. Microbiol. 65:5372-5377.

[41]. Salanitro, J.P., Blake, I.G., Muirhead, P.A., 1977. Types and distribution of anaerobic bacteria in the large intestine of pigs. Appl. Environ. Microb. 37, 187-193.

[42]. Schmidt-Willig U, Enss M, Coenen M, Gartner K and Hedrich H 1996. Response of rat colonic mucosa to a high fiber diet. Annals of Nutrition and Metabolism 40, 343-350.

[43]. Schneeman, B. O. 1987. Dietary fiber and gastrointestinal function. Nutr. Rev. 45:129-132.

[44]. Schneeman BO, Diane Richter B and Jacobs LR 1982. Response to dietary wheat bran in the exocrine pancreas and intestine of rats. The Journal of Nutrition 112, 283-286.

[45]. Stephen, A.M., 1994. Whole grains - impact of consuming whole grains on physiological effects of dietary fiber and starch. Crit. Rev. Food Sci. Nutr. 34, 499-511.

[46]. Trowell, H., Southgate, D.A.,Wolever, T.M., Leeds, A.R., Gassull, M.A., Jenkins, D.J., 1976. Letter: dietary fibre Refined. Lancet 1, 967.

[47]. Varel VH and Yen JT 1997. Microbial perspective on fiber utilization by swine. Journal of Animal Science 75, 2715-2722.

[48]. Varel VH, Pond WG, Pekas JC and Yen JT 1982. Influence of high-fiber diet on bacterial populations in gastrointestinal tracts of obese- and lean-genotype pigs. Applied and Environmental Microbiology 44, 107-112.

[49]. Wenk C 2001. The role of dietary fibre in the digestive physiology of the pig. Anim Feed Sci Technol., 90: 21-33

[50]. Wilfart A. et al., 2007. Effect of fibre content in the dieton the mean retention time in different segments of thedigestive tract in growing pigs. Livest. Sci., 109, 27-29.

[51]. Williams BA, Verstegen MWA and Tamminga S 2001. Fermentation in the large intestine of singlestomached animals and its relationship to animal health. Nutrition Research Reviews 14, 207-227.

[52]. Yin, Y. L., McEvoy, J. D. G., Schulze, H., Hennig, U., Souffrant, W. B., McCracken, K. J., 2000. Apparent digestibility (ileal and overall) of nutrients and endogenous nitrogen losses in growing pigs fed wheat (var. Soissons) or its by-products without or with xylanase supplementation. Livest. Prod. Sci. 62, 119-132.

[53]. Zervas, S., Zijlstra, R. T., 2002a. Effects of dietary protein and fermentable fiber on nitrogen excretion patterns and plasma urea in grower pigs. J. Anim. Sci. 80, 3247-3256.

Citation: N. Gamachu Dinsa, "Review on Fiber Digestion in Non Ruminant Animals and Effect of Dietary Fiber", International Journal of Research Studies in Agricultural Sciences (IJRSAS), vol. 3, no. 10, p. 8, 2017. http://dx.doi.org/10.20431/2454-6224.0310004

Copyright: (C) 2017 Authors. This is an open-access article distributed under the terms of the Creative Commons Attribution License, which permits unrestricted use, distribution, and reproduction in any medium, provided the original author and source are credited. 